\title{
Ruminant Livestock Production System Adaptation Strategies to Climate Change: A Review
}

\author{
Abdi Hassen ${ }^{1, *}$, Ibsa Dawid ${ }^{2}$ \\ ${ }^{1}$ East Hararghe, Meta Agricultural Office, College of Agriculture and Environmental Sciences, Africa Center of Excellence for Climate \\ Smart Agriculture and Biodiversity Conservation, Department of climate smart agriculture, Haramaya University, Haramaya, Oromia, \\ Ethiopia. \\ ${ }^{2}$ Socio-Economics Research Team, Asella Agricultural Engineering Research Center, Oromia Agricultural Research Institute, P. O. Box \\ 06, Asella, Ethiopia.
}

How to cite this paper: Abdi Hassen, Ibsa Dawid. (2021) Ruminant Livestock Production System Adaptation Strategies to Climate Change: A Review. OAJRC Environmental Science, 2(1), 7-16.

DOI: 10.26855/oajrces.2021.11.001

Received: October 12, 2021

Accepted: November 8, 2021

Published: November 25, 2021

*Corresponding author: Abdi Hassen, East Hararghe, Meta Agricultural Office, College of Agriculture and Environmental Sciences, Africa Center of Excellence for Climate Smart Agriculture and Biodiversity Conservation, Department of climate smart agriculture, Haramaya University, Haramaya, Oromia, Ethiopia.

Email: abd51042@gmail.com

\begin{abstract}
Climate change affects ruminant livestock production systems through direct impacts on animal physiology and production, while indirectly through feed availability, water availability composition, and quality. These impacts may be positive or negative and will vary across geographical regions, animal species, and adaptive capacity. The ruminant animal productions have several adaptive mechanisms to maintain homeostasis through behavioral, physiological, and morphological. The Potential adaptation strategies involve land-use decisions, animal feeding changes, genetic manipulation, breeding, and species improvement, and alteration. Integrated livestock-crop production systems can reduce impact, and increase productivity, diversify production, and enhance resiliency ruminant livestock productions. So, adaptation strategies of ruminant livestock's productions have ability to survive, and reproduce in the conditions of poor nutrition, parasites, and diseases, as well as their tolerance to heat. Pastoral Mobility was a survival and resource management strategy commonly practiced by herder societies for increased adaptability to climate changes. Ruminant livestock is also an important component of all farming systems and provide draught power, milk, meat, manure, hides, skins, and other products for most countries. A review of this seminar paper was prepared on the adaptation of the ruminant livestock production system strategies to climate change. Effective adaptation strategies to minimize negative impacts on ruminant production systems due to climate change will need to be multi-dimensional.
\end{abstract}

\section{Keywords}

Climate Change, Adaptation, Ruminant Livestock, Strategies, Productions System

\section{Introduction}

Ruminant livestock is a global resource for both developing and developed countries. They provide multiple benefits that include food, clothing, fuel, nutrient cycling for soils, draught, income and employment, and a means of future food and income insurance against climate and weather-associated [1]. The global surface temperature was increasing on average by $0.81^{\circ} \mathrm{C}$ above the 20th century [2]. This may cause an increased temperature, changes in the amount of rainfall, and shifts in precipitation patterns, and an increased frequency of extreme weather events and impact on livestock [3]. The effects of climate change on livestock productions will vary by region, animal species, and product type and may be positive or negative [4]. Climate change leads to reductions in livestock productivity by directly depressing animals' adaptive response mechanisms, 
altering the spread and prevalence of diseases and causing heat stress and increased competition for resources [5] and indirectly by compromising the availability of feed crops and quality of forages [6].

According to Feleke [7], climate change had thermal, nutritional, and water-related stresses, restlessness, and affected livestock productivity. Among the ruminant livestock species, especially small ruminants like sheep and goats, are more vulnerable to climate change due to their heavy reliance on climate-sensitive resources and immobility during floods [8] and may not adapt to extreme climate change events such as shortages of fodder, floods, and droughts [9]. Even though such kinds of stress exist, ruminant livestock resistance to climate change, improving productivity, modifying the environment, and improving nutritional management due to increased adaptability [10]. Ruminant livestock has optimal temperature ranges for growth and comfort known as the thermo neutral zone (TNZ) that depend on the species, animal age and physiological state, relative humidity, and other factors. Within the TNZ, ruminant livestock has the highest productivity and most efficient conversion of feed [11]. If temperatures are too cold, metabolism may increase, reducing growth. Low temperatures will result in increased feed intake to meet increased maintenance energy needs [12]. Above the TNZ, heat stress may lead to decreased feed intake and production, increased mortality, or decreased reproduction. With climate change, the issue is how temperatures at a particular location change relative to different species of TNZ [11].

The processes by which domestic animals respond to changes in their environment are critical to survival, but often negatively affect the productivity and profitability of livestock systems [10]. Livestock producers have traditionally adapted to environmental and climate change. The interactions of livestock with their environment are complex and depend on location and management practices. Most traditional ruminant livestock production systems are resource-driven, making use of locally available resources with limited alternative uses. In mixed production systems, traditionally managed ruminant livestock often provides valuable inputs to crop production, ensuring close integration [13]. The best adaptation options will combine technological, behavioral, management, and policy options to effectively offset the negative effects of climate change and maximize any benefits. Adaptation in the form of genetic manipulation, breed change, and/or species change may be needed [14]. For instance, the differentiation of goats from cattle may be in order as (a) goats are better adapted to hotter conditions; (b) goats possess skillful grazing behavior, and (c) the goat digestive system is more efficient as the rumen can serve as a fermentation vat and water reservoir. One should note that animal physiology and genetics limit an animal's adaptive capacity and that livestock breeders can alter traits to enhance adaptation [15].

Incremental adaptations (simple adjustments to existing farming systems) [16] which are applicable on a range of time scales can be one of the activities or maybe on a historical trend of progress, for example, animal genetic improvement [17]. The importance of this review was that ruminant livestock production strategies has the potential to strengthen resilience to climate change and that ruminant livestock production systems tend to be more adaptive than crop-based production systems [9]. Ruminant livestock production farming is a crucial adaptation mechanism for poor and vulnerable people in variable environments where there are many risks. Adaptation is based on the resistance mechanisms of ruminant animals to climatic conditions, diseases, and food shortages, on the ability of these animals to make effective use of the diversity of plant species, on the rapidly deployable standing capital function, and on mobility. The diversity of ruminant livestock production systems also enhances the range of adaptation capacities [18]. There are different directions where ruminant livestock production adapted to climate change. So in this review, we explain the basic information on the extent and effectiveness of ruminant livestock production responses to climate elements such as temperature and to extreme events based on the literature. The main objectives of this seminar papers was to address the ruminant livestock production systems adaptation options to climate change.

\section{Ruminant Livestock Production System Adaptation Strategies’ to Climate Changes}

\subsection{Concept and Definition of Ruminant Livestock adaptation strategies to Climate CC}

Livestock, which includes ruminant and monogastric species, accounts for $18 \%$ of global calorie consumption and $25 \%$ of global protein consumption. Ruminant livestock such as cattle, buffalo, sheep, and goats generate high amount of protein every year, according to estimates [19]. Adapted ruminant Livestock productions are an important component of nearly all farming production systems and provide draught power, milk, meat, manure, hides, skins, and other products [20]. Climate change is defined as a long-term trend that implies a movement in the climate over a decade [3].

Adaptation to climate change is one of the pillars of Climate smart agriculture (CSA) and the process of making changes in natural or human systems in response to present or anticipated climatic stimuli or their effects, to moderate damage or take advantage of positive opportunities [21]. Changes in animal management systems by developing tolerant breeds, improving water access, improving pasture species, nutritional interventions, provision of shade, housing, fans, and sprinklers are among the adaptation ruminant livestock production systems adjustments and genetic improvement for thermo-tolerance and their strategies used to sustain ruminant production. Approaches such as ruminant animal breeding, diet, housing, and health are necessary to reduce the negative effects of climate change on livestock [22]. The adaptive capacity of a ruminant livestock 
production system refers to its ability to adapt to climate change, particularly climate variability and extremes, to mitigate possible damage, seize opportunities, or cope up with the consequences [4].

There are a variety of methods available to help ruminant livestock owners adjust to CC. Diversification, intensification, and integration of pasture management, livestock, and crop production; changing the timing of operations; conserving nature and ecosystems; modifying stock routings and distances; and introducing mixed livestock farming systems and pasture grazing are all possible changes in ruminant livestock production systems [23].

\subsection{Climate Change affecting ruminant Livestock Production Systems}

Potential impacts of climate change on livestock include direct effects on animal physiology, production, and behavior [1] and indirect effects changes in water availability and the quantity and quality of forage and feed crops [24]. Factors influencing these effects include increases in atmospheric levels of carbon dioxide $\left(\mathrm{CO}_{2}\right)$, higher temperatures, and changes in the amount, seasonality, and variability of precipitation [1]. Climate change impacts with a $2^{\circ} \mathrm{C}$ average global temperature rise may be more severe as estimated by the IPCC.

Much of the world's grasslands and grazing areas are found in the tropics and subtropics, as are some of the world's poorest people who rely on those lands for food security. In these areas, where socio-economic variables such as reliance on local food production and vulnerability to land degradation add to the risk of food insecurity, ruminant livestock is crucial to providing nutritional demands. While societies have traditionally coped with high climate fluctuation by adopting locally adapted animal breeds that are more resilient than many temperate phenotypes, future capability to cope with hotter, drier, and more extreme conditions may necessitate more adaptation expenditure [14].

\subsection{Ruminant livestock production system adaptation strategies to climate change}

Global food security and the growing demand for animal products related to a rising population and increasing income emphasize the importance of climate adaptation strategies to minimize adverse impacts on animal production. However, ruminant livestock is one of the food and fibre production systems most vulnerable to climate change, and also rangelands occupied by ruminant animals in tropical and subtropical regions are sensitive to the impacts of climate change, with more than 50\% of total meat and $60 \%$ of milk produced in these zones [19]. Ruminant livestock has physiological characteristics that are unique traits, such as disease resistance and drought tolerance, and represent an important source of genetic diversity that animal breeders can use in responding to pest and disease outbreaks and climate change [20]. Responses to direct impacts on ruminant animals include changes in feed management likes as balancing feed, forage, supplements, stocking rates, genetic selection, disease risk management, climate control and timing of reproduction [25]. Adaptation to climate change refers to adjustments in natural or human systems in response to actual or expected climatic stimuli or their effects, which moderate farming or exploit beneficial opportunities [21].

\subsubsection{Pastoral ruminant productions system to climate change}

Adjustment of pastoral ruminant livestock productions practices comprised of a number of adaptation choices. These are increased mobility, more adoption of drought-tolerant ruminant livestock species, increasing resort to purchased hay, competitive individual household land grabs for strategic private range enclosures for the double purpose of cereal cultivation, and fodder production [25]. Ruminant species will have the ability to cope with climate change, especially goats, because they are tolerable to heat stress, and hence desirable species to rear at high temperature zones [26]. The ability of goats to cope with stress due to their ability to produce higher plasma flow of cortisol when exposed to multiple stressors and important species difference that should be considered when selecting/breeding for production in regions with extreme climatic conditions [28]. Farmers and pastoralists need to switch to ruminant species and breeds that can cope with the prevailing weather conditions, producing meat and milk in poor conditions requiring less input and low environmental impact. Goats can tolerate the changing climate because they are efficient desert dwellers, and they have high digestive efficiency for survival in harsh climatic conditions [22, 26].

\section{(1) Ruminant livestock Mobility strategies}

Mobility remains the most important pastoralist adaptation to spatial and temporal variations in precipitation. Encouraging mobility was a strategic reaction to the variability and scarcity of pastures. According to [3] increasing livestock mobility, a traditional strategy of nomadic and transhumance herders for matching animal production needs with changing range land resources, can significantly enhance the resilience of these livestock systems to climate change. During ruminant livestock mobility, the nomads adapted their production to the difficult eco-climatic situations and developed a natural resource management system implemented by consensus and pastoral solidarity, as well as shared responsibility [29]. The primary adaptation was the replacement of herds by goats because of their capacity for adaptation and their reduced food requirements, with the 
addition of some camels and cows [30]. As many pastoral communities are becoming less mobile, they become more vulnerable to the effects of climate change. Shocks brought about by climate-driven variability in livestock production can be buffered by ruminant livestock production through ruminant animal movements, adjustments in feed baskets, health interventions, and animal off-take for the market [31]. However, livestock may be required to walk long distances in search of feed and have to cope with less frequent watering due to climate change [29].

\subsubsection{Mixed crop ruminant livestock productions system to climate change}

Bringing of mixed ruminant livestock farming system is a strategy for adapting to climatic change [32]. According to [33], integrated livestock-crop production systems are an emergent management strategy and as [34] stated that integrated livestock-crop production systems can reduce enterprise risk, restore degraded land, increase productivity, diversify production, and enhance resiliency of the land. For more, by integrating ruminant livestock with crops as well as with forests, manure from livestock can be used as fertilizer to improve soil nutrient status and soil organic matter [33]. Large ruminant livestock is very popular among ruminant farmers and these include cattle, buffalo, camel, etc. Among the large ruminants, cattle production has been improved with specializations in milk and meat industry. Small stock species such as goat and sheep are key species in the tropics and the subtropics because they are well adapted and could begin to dominate over large stock species owing to their grazing or browsing capabilities [35].

\subsubsection{Diversification ruminant livestock productions system to climate change}

Keeping different livestock species is one of the adaptive measures in climate change and also diversification is an essential adaptation strategy with economic value to boost smallholder adjustment during climatic stress [36]. Heat wave and drought tolerance can be improved by diversification and production during climatic stress. The ability of diversification to limit pests and diseases caused by climate change and improve the productivity of ruminants [37]. Diversification of livestock and crop varieties can increase drought and heat wave tolerance and may increase livestock production when animals are exposed to temperature and precipitation stresses. So, diversity of ruminant livestock with crops is effective to decrease climate change-related diseases and pest outbreaks [38, 39].

\subsection{Ruminant livestock adaptive mechanisms to climate change}

Adaptation of ruminant livestock to different locations depends upon prevailing climatic conditions, type of feed availability, species, and breed. Some of these, like small ruminants, camels, can tolerate a very high range of temperatures and have the capacity to convert low-quality forage to quality animal protein [4]. Ruminant livestock has physiological adaptability and primary response mechanisms that aid animal survival during exposure to high heat load. Exposure of animals to heat load induces an increase in the dissipation of excess body heat into the environment to reduce the heat load on their bodies [40]. Reducing body heat at night helps the animals cope with higher temperatures during the daytime. Respiration rate and rectal temperature are ideal indicators for quantifying heat stress in several ruminant species [41]. There are also behavioral adaptations that respond to heat-stressed include shade seeking, reduced feed intake, increased water intake and drinking frequency, increased standing time, decreased lying time, and reduced defecation and urination frequency [5,42].

\subsection{Adaptive response of livestock production to climate change}

\subsubsection{Climate change forage production and quality}

Climate change effects on productivity and quality of pasture and forage consumed by ruminant livestock are expected to be regionally specific. In temperate regions, the effects of climate change on grassland production may be positive due to prolonged growth with slight increases in ambient air temperature combined with elevated $\mathrm{CO}_{2}$, provided water and nutrient supplies are not limited. In tropical and sub-tropical rangelands, both high temperatures and water scarcity appear more likely to result in lower forage quantity under future climate. In both regions, the nutritive value of forages may decrease as crude protein (CP) and digestibility decline [22]. Ruminant livestock production systems that are adapted to this area are more productive than those in the hot areas. The increasing temperature and declining precipitation decreased forage CP content and increased the ratio of digestible organic matter to CP content for regions with continental climates. In temperate high rainfall climates, particularly in dairy pastures where nitrogen $(\mathrm{N})$ fertilizer is applied, pasture protein levels are typically more than animal requirements for much of the year [20].

\subsubsection{Adapting to changing water security}

Water is the most important input in ruminant livestock production systems, mainly in feed crop production [18]. Climate change affects water availability, and water scarcity and depletion are reported to seriously reduce livestock productivity [43]. 
Water intake by livestock is related to animal size, age, diet, animal activity, temperature, and physiological status of animals (lactation and growth rate). The drinking of water for cattle should be between $5^{\circ} \mathrm{C}$ and $18^{\circ} \mathrm{C}$ and when the ambient temperature exceeded $27^{\circ} \mathrm{C}$, water and feed intake decreased, negatively affecting animal productivity [17]. In response to global warming, adaptation strategies will be needed to meet freshwater requirements, in terms of both quantity and temperature, for both productivity and welfare of ruminants [37]. In rangelands, increasing the number of watering points will reduce the distance animals have to walk to drink and will have the co-benefit of encouraging more even pasture utilization. These extensive systems, including shade over watering points will reduce evaporative loss, reduce water temperatures, increase the efficacy of water intake by animals and thus assist with reducing heat stress [22].

\subsubsection{Adaptive response of ruminant livestock production system to heat stress}

The adaptive capacity of ruminant animals is generally evaluated by assessing the ability to produce under extreme climates, and the capacity to show minimal deleterious effects on production, lower mortality rates, and maintenance of reproductive efficiency. Indigenous breeds that have evolved in tropical and subtropical regions have a higher adaptive capacity to heat stress than exotic breeds. The adapted local breeds can be better alternatives as an appropriate bio-resource to sustain small ruminant production under changing climatic conditions [41].

Ruminant livestock normally maintains their body temperature within a fairly narrow range $\left(0.5^{\circ} \mathrm{C}\right)$ [44]. When animals are exposed to combinations of high temperature, solar radiation, and humidity and are not able to adequately dissipate accumulated heat, heat stress occurs [4]. A heat stress response can be influenced by numerous factors: species, breed, previous exposure, health status, level of performance, body condition, age, coat color, lactation stage and body condition [22, 44]. The negative effects of heat stress include compromised metabolic and digestive functions that reduce milk production and quality, compromise animal welfare, reduce reproductive efficiency, and, in extreme cases, cause death [44, 45]. A heat stress response can be influenced by numerous factors: species, breed, previous exposure, health status, level of performance, body condition, age, coat colour, lactation stage, and body condition [14]. Animals within the same breed exhibit greater tolerance to heat stress due to genotypic differences because those animals have a range of optimum environmental temperature requirements [46].

\subsection{Adaptation options for ruminant livestock production to climate change}

Adaptation strategies can improve the resilience of crop and livestock productivity to climate change [47]. Adaptation measures involve production and management system modifications, breeding strategies, institutional and policy changes, science and technology advances, and changing farmers' perceptions and adaptive capacity [39, 47]. Adaptation strategies ruminant livestock productions address not only the tolerance of livestock to heat, but also their ability to survive, grow and reproduce in conditions of poor nutrition, parasites and diseases. Such measures could include: (i) identifying and strengthening local breeds that have adapted to local climatic stress and feed sources, and (ii) improving local genetics through cross-breeding with heat and disease-tolerant breeds [32].

\subsubsection{Ruminant livestock management system}

The impacts of extreme heat load events on livestock can be adapted by adjusting their environment and diet, and by selecting animals that are more heat tolerant [15]. An adaptation such as the modification of production and management systems involves diversification of livestock animals and their feed, integration of livestock systems with forestry and crop production, and changing the timing and locations of farm operations [39].

In addition, adjusting the animals' environment and improving the ability of the animal to dissipate body heat can include providing shade, sprinklers, misters, and fans, but ensuring access to adequate drinking water is paramount [14]. The impact of extreme and variable climate conditions like heat stress can be reduced by housing and management measures. Proper housing can prevent heat stress, especially when the temperature and air refreshment rate can be regulated. In countries where capital is available, industrial, specialized breeds can effectively increase production more or less independently of climate conditions. Improvements in housing and management can be seen as a climate adaptive measure by itself [48].

\subsubsection{Ruminant livestock genetic/breed strategies}

\section{(1) The Potential for genetic improvement of ruminant livestock}

Ruminant livestock production is selected for meat, fleece, and milk production, and breeding objectives also incorporate other functional attributes such as reproductive efficiency and disease resistance. A ruminant livestock genetic flexibility to adapt to extreme environment reflects in its productive and reproductive performances [40]. However, higher sensitivity to sudden environmental disturbances has become a major issue due to climate change. The best mechanism to tolerate climate 
change is to rear local breeds adapted to harsh environments. Most developed country breeds have been studied for the past many decades in case the climate is managed [49]. The selection of animals is a cost-effective, cumulative, and permanent strategy that exploits natural variation among breeds for desirable traits. Thus, improved animal genetics can contribute to both adaptation and mitigation approaches to sustain animal production in the changing climate scenario [41]. Important traits in such selection schemes are skin and hair type, sweat gland capacity, reproduction rate, ability to maintain productivity in difficult conditions, resistance to local diseases and parasitic infestation, metabolic heat production, tolerance to drought, and anatomic and morphologic structure are some important impacts which are likely to derive from climate change [50].

\section{(2) Species/Breed selection strategies to adapt to ruminant livestock production systems}

Indicators of animal performance such as weight gain, milk production, wool production, and reproductive efficiency were influenced by ambient temperature, humidity, and wind speed. The effect of climate change on animals' productive function depends on the animal's adaptive potential, which is a relative function of its species and breeds [51]. In warmer locations, producers favored goats and sheep rather than beef cattle and chickens because farmers may adapt to climate change by shifting from crop production towards livestock production, or mixed farming systems, with a shift in the animal species most suited to the local environmental conditions. An animal's genetic flexibility to adapt to extreme environments is reflected in its productive and reproductive performances [40].

Breeding is essential to increase livestock productivity or resilience to certain conditions by improving productive traits such as weight gain, milk yield, and fertility [31]. Changes in breeding strategies can help animals increase their tolerance to heat stress and diseases and improve their reproduction and growth development [14]. In addition, policy measures that improve adaptive capacity by facilitating the implementation of adaptation strategies will be crucial [47]. For example, developing international gene banks could improve breeding programs and serve as an insurance policy [37].

Many ruminant livestock local breeds are already adapted to harsh living conditions and well adapted to the local climate, but production levels of local breeds are usually lower, compared to specialized, more widely used breeds [48]. Genetic selection under optimal temperature and humidity conditions and frequently tailored to more intensive systems in temperate climates. This approach may result in animals that are less adaptive to less favorable conditions [14]. Natural selection for local ruminant livestock breeds has favored with higher heat tolerance that is more able to cope with thermal variations, stress, and tropically adapted breeds also have a greater capacity to grow and reproduce during unfavorable seasonal conditions with poor nutrition and higher disease and parasite pressures than high-performance breeds of temperate [52]. So during Breeds and species selections that are more adapted to local C are acceptability. According to [53], breed choice between Bostaurus, Bosindicus, and composite breeds in Texas, finding summer heat stress influenced breed selection, with heat stress favoring Bosindicus, while reducing Bostaurus and composite breeds. Different ruminant livestock species or breeds respond differently to climate alterations and those livestock producers can adapt to CC by changing species or breeds [54].

\subsubsection{Production adjustments and developing more productive climate-adaptive breeds}

The practices that can be changed to increase climate resilience are (i) diversification, intensification, and/or integration of pasture management, livestock, and crop production; (ii) changing land use and irrigation; (iii) altering the timing of operations; (iv) conservation of nature and ecosystems; (v) modifying stock routings and distances; (vi) introducing mixed livestock farming systems, such as stall-fed systems and pasture grazing [32]. To generate breeds with increased output while keeping climate-adaptive traits, well-considered breeding programs are required. While there is often a short-term focus on expanding production and a lack of long-term policies, breeding programs are long-term investments. Breeding firms spend a lot of money developing specific breeds for specific settings, and it's not always viable for them to do so. To connect public and private interests, breeding programs in tropical countries or countries with extreme or unpredictable climates could be formed through public-private partnerships and investments by leading breeding businesses [48].

\subsubsection{Capacity building for ruminant livestock producers}

There is a need to improve the capacity of livestock producers and herders to understand and deal with climate change, increasing their awareness of global changes. Ruminant animals' capacity to minimize influenced by disturbances or to quickly return to the resting state before the disturbance is called resilience [55]. Efficient and affordable adaptation practices for ruminant livestock production need to increase their productivity [56]. These could include: (i) provision of shade and water to reduce heat stress from increased temperatures; (ii) reduction of livestock numbers; a lower number of more productive animals leads to more efficient production and lower GHG emissions from livestock production [39]; (iii) changes in livestock/herd composition (selection of large animals rather than small); (iv) improved management of water resources through the introduction of simple techniques for localized irrigation, accompanied by infrastructure to harvest and store rainwater [57]. The more information's of ruminant livestock adaptations strategies are summarized in Table 1. 
Table 1. Short summery of Ruminant livestock adaptation options (strategies)

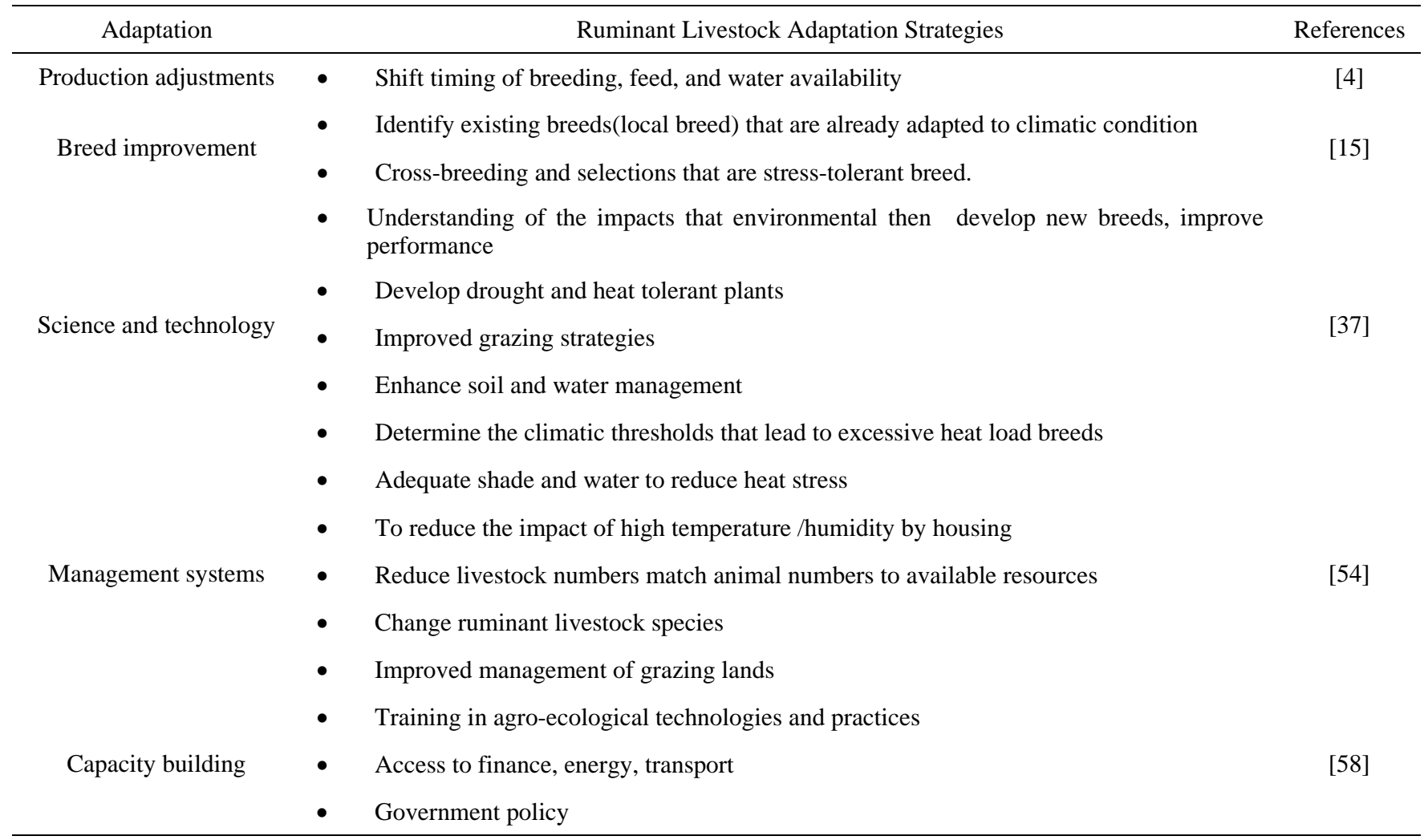

\section{Conclusions and Recommendations}

Ruminant livestock can determine their role in attaining food security in the face of climate change and will continue to contribute significantly to the global food supply. The evaluations stress the necessity of ruminant livestock production system adaptability to climate change, as well as the ability to maintain productivity in challenging conditions by tolerating various settings.

Adaptation tactics address ruminant livestock's ability to survive, thrive, and reproduce in conditions of poor nutrition, parasites, and diseases, as well as their tolerance to heat through physiological, morphological, and behavioral changes. This will be accomplished by various methods available to help ruminant livestock owners adjust to climate change. Diversification, intensification, and integration of pasture management, livestock, and crop production; changing the timing of operations; conserving nature and ecosystems; modifying stock routings and distances; and introducing mixed livestock farming systems and pasture grazing are all possible changes in the ruminant livestock production system through identifying and strengthening local breeds that have adapted to local climate conditions and feed sources, as well as improving local genetics through cross-breeding that adapts heat-tolerant. The adaptation of ruminant livestock production to climate variability is a valuable way to keep ruminant production going in a changing climate.

For prospects, the most important future approach to dealing with climate change, the section emphasizes creating a sustainable improvement of agro-ecological ruminant livestock breeds with increased thermal tolerance and determining the rate of natural selection between forage species. Genetic selection-based improvements in ruminant livestock are low. Therefore, developing long-term genetic improvement strategies to mitigate climate change is crucial. Diversification can be an important element of climate change adaptation of ruminant livestock productions, farmer's and farming community' capacity building to manage diversification and mixed crops and ruminant livestock.

\section{References}

[1] Henry, B., Charmley, E., Eckard, R., Gaughan, J. B., Hegarty, R., (2012). Livestock production in a changing climate: adaptation and mitigation research in Australia. Crop Pasture Sci., 63, 191-202. 
[2] Adler, R., M. Sapiano, G. Huffman, J. Wang, G. Gu, D. Bolvin, L. Chiu, U. Schneider, A. Becker, E. Nelkin, P. Xie, R. Ferraro, D. Shin. (2018). The Global Precipitation Climatology Project (GPCP) Monthly Analysis (New Version 2.3) and a Review of 2017 Global Precipitation. Atmosphere, 9(4), 138; DOI: 10.3390/atmos9040138.

[3] FAO. (2021). Climate-smart livestock production. A practical guide for Asia and the Pacific region. Bangkok. https://doi.org/10.4060/cb3170.

[4] Sejian, Veerasamy, and John Gaughan. (2015). Climate Change Impact on Livestock : Adaptation and Mitigation. edited by I. VeerasamySejian Animal Physiology Division ICAR-National Institute of Animal Nutrition and Physiology Bangalore, Karnataka.

[5] Aleena, J., V. Sejian, M. Bagath, G. Krishnan, V. Beena, and R. Bhatta. (2018). The resilience of three indigenous goat breeds to heat stress based on pheno-typic traits and PBMC HSP70 expression. Int. J. Biometeorol., 62: 1995-2005. Doi: 10.1007/s00484-018.

[6] Reidsma, P., Wolf, J., Kanellopoulos, A., Schaap, B. F., Mandryk, M., Verhagen, J., van Ittersum, M. K. (2015). Climate change impact and adaptation research require farming systems analysis and integrated assessment: A case study in the Netherlands. Procedia Environ. Sci., 29, 286-287.

[7] Feleke, F. B., Berhe, M., Gebru, G., and Hoag, D. (2016). Determinants of adaptation choices to climate change by sheep and goat farmers in Northern Ethiopia: the case of Southern and Central Tigray, Ethiopia. Springer Plus, 5(1), pp. 1-15.

[8] Abdeta, A. (2011). Effects of drought on cattle herd dynamics and its implication on local livelihood systems in Borana, Ethiopia. Food Security Center (FSC) Brief, pp. 1-6.

[9] Sahoo, A., Kumar, D., Naqvi, S. M. K. (2013). Climate-resilient small ruminant production. In Sahoo A, Kumar D, Naqvi SMK (Eds.) National Initiative on Climate Resilient Agriculture (NICRA) Izatnagar, India: pp. 1-106.

[10] Bernabucci, U. (2019). From the Editor Climate change: impact on livestock and how can we adapt. 9(1). https://doi.org/10.1093/af/vfy039.

[11] Hristov, A. N., Degaetano, A. T., and Rotz, C. A. (2017). Climate change effects on livestock in the Northeast US and strategies for adaptation. https://doi.org/10.1007/s10584-017-2023-z.

[12] NRC. (2016). Nutrient requirements of beef cattle, 8th reviews. Natl. Acadia, Washington, D.C. doi: 10.17226/19014.

[13] FAO. (2009). The state of food and agriculture: Livestock in the balance. Food and Agriculture Organization of the United Nations. http://www.fao.org/.

[14] Henry, B. K., Eckard, R. J., and Beauchemin, K. A. (2018). Review: Adaptation of ruminant livestock production systems to climate changes.

[15] Gaughan, J., Cawdell-Smith, A. J. (2015). Impact of Climate Change on Livestock Production and Reproduction: Adaptation and Mitigation; New Delhi, India; pp. 51-60, ISBN 978-81-322-2264-4.

[16] Rickards, L., Howden, S. M. (2012). Transformational adaptation: Agriculture and climate change. Crop. Pasture Sci., 63, $240-250$.

[17] Moore, A. D., Ghahramani, A. (2014). Climate change and broad acre livestock production across southern Australia. 3. Adaptation options via livestock genetic improvement. Anim. Prod. Sci., 54, 111-124.

[18] Vigne, M., Blanfort, V., Vayssières, J., Lecomte, P., and Steinmetz, P. (2016). Livestock farming constraints in developing countries from adaptation to mitigation in ruminant production systems. In Climate Change and Agriculture Worldwide (pp. 127-141).

[19] Mottet, A., de Haan, C., Falcucci, A., Tempio, G., Opio, C., and Gerber, P. (2017). Livestock: on our plates or eating at our table? A new analysis of the feed/ food debate. Global Food Security, 14, 1-8.

[20] Weindl, I., Hermann, L. C., Alexander, P., Christoph, M., Petr, H., Mario, H., Christoph, S., and Susanne, R. (2015). Livestock in a changing climate: production system transitions as an adaptation strategy for agriculture. Environ. Res. Lett., 10, 094021.

[21] Malik, A., Qin, X., and Smith, S. C. (2010). Autonomous adaptation to climate change: A literature review. Institute for International Economic Policy Working Paper Series, pp. 1-25.

[22] Gaughan, J. B., S. Veerasamy, T. L. Mader, and F. R. Dunshea. (2019). Adaptation strategies: ruminants. Anim. Front., 9(1): 47-53.

[23] Thornton, P. K., Herrero, M., Freeman, A., Mwai, O., Rege, E., Jones, P., McDermott, J. (2008). Vulnerability, climate change and livestock: Research opportunities and challenges for poverty alleviation. International Livestock Research Institute (ILRI), Kenya.

[24] Craine, J. M., Elmore, A. J., and Angerer, J. P. (2017). Long-term declines in dietary nutritional quality for North American cattle. Environmental Research Letters 12, 044019.

[25] Hoekstra, N. J., Suter, M., Finn, J. A., Husse, S., and Lüscher, A. (2015). Do belowground vertical niche differences between deep and shallow-rooted species enhance resource uptake and drought resistance in grassland mixtures? Plant Soil, 394, 21-34.

[26] Berhanu, W., Beyene, F. (2014). The impact of climate change on pastoral production systems: A study of climate variability and household adaptation strategies in southern Ethiopian rangelands. WIDER Working Paper, No. 2014/028, ISBN 978-92-9230-749-3. 
[27] Reddy, P. R. K., Kumar, D. S., Rao, E. R., et al. (2019). Environmental sustainability assessment of tropical dairy buffalo farming vis-a-vis sustainable feed replacement strategy. Sci Rep-UK 9: 16745. https://doi.org/10.1038/s41598-019-53378.

[28] Grandin, T. and Whiting, M. (Eds.) (2018). Are We Pushing Animals to Their Biological Limits? Welfare and Ethical Implications.

[29] Tibbo, Markos. (2012). Livestock and Climate Change in the Near East Region. CAIRO.

[30] Khattry Ould Attigh, M. (2011). Islamic Republic of Mauritania country paper. Second forum on climate change in the Near East Climate Change, Agriculture and Food Security. Cairo, Egypt, Regional Office for the Near East, FAO.

[31] FAO. (2016). “Livestock \& climate change.” www.Fao.Org/Climate-Change.

[32] IFAD. (2009). Livestock and climate change. Livestock Thematic Papers Tools for Project Design Livestock, $44-00142$. www.ifad.org/climate/Rome; Italy.

[33] Sulc, R. M. and A. J. Franzluebbers. (2014). Exploring integrated crop-livestock systems in different ecoregions of the United States. European Journal of Agronomy, 57: 21-30.

[34] Palmer, L. (2014). A new climate for grazing livestock. Nature Climate Change, 4: 321-323.

[35] Rout, P. K. and Behera, B. K. (2021). Sustainability in Ruminant Livestock: Management and Marketing. Springer Nature.

[36] Gezie, M. (2019). Farmer's response to climate change and variability in Ethiopia: A review. Cogent Food \& Agriculture, 5(1), p. 1613770.

[37] Thornton, P. K. and Herrero, M., (2014). Climate change adaptation in mixed crop-livestock systems in developing countries. Global Food Security, 3(2), pp. 99-107.

[38] Batima, P., Bat, B., Tserendash, L., Bayarbaatar, S., Shiirev-Adya, S., Tuvaansuren, G., Natsagdorj, L., Chuluun, T., (2005). Adaptation to Climate Change, Vol. 90. ADMON Publishing, Ulaanbaatar.

[39] IFAD (International Fund for Agricultural Development). (2010). Livestock and climate change. http://www.ifad.org/lrkm/events/cops/ papers/climate.pdf.

[40] Da Silva, R. de Sousa, W. P. Costa, W. S. T. da Silva, M. M. Guilhermino, L. A. B. Asensio, and D. A. E. Façanha. (2017). Daily rhythmicity of the thermoregulatory responses of locally adapted Brazilian sheep in a semiarid environment. Int. J. Biometeorol., 61: 1221-1231. DOI: 10.1007/s00484-016-1300-2.

[41] Joy, A., Dunshea, F. R., Leury, B. J., Clarke, I. J., Digiacomo, K., and Chauhan, S. (2020). The resilience of Small Ruminants to Climate Change and Increased Environmental Temperature: A Review. www.Mdpi.Com/Journal/Animals.

[42] Valente, É. E., M. L. Chizzotti, C. V. de Oliveira, M. C. Galvão, S. S. (2015). Intake, physiological parameters, and behavior of Angus and Nellore bulls subjected to heat stress. SeminCiêncAgrár., 16: 4565-4574. Doi: 10:5433/1679.2015v36nb6sup1234565.

[43] Akinmoladun, O. F., Muchenje, V., and Fon, F. N. (2019). Small ruminants: farmers' hope in a world threatened by water scarcity. Animals, 9(7), p. 456.

[44] Das, R., Sailo, L., Verma, N., Bharti, P., Saikia, J., Imtiwati, and Kumar, R. (2016). Impact of heat stress on health and performance of dairy animals: a review. Veterinary World, 9, 260-268.

[45] Gauly, M., Bollwein, H., Breves, G., Brügemann, K., Dänicke, S., Demeler, J., Hansen, H., Isselstein, J., and Lohölter, M. (2013). Future consequences and challenges for dairy cow production systems arising from climate change in Central Europe a review. Animal, 7 , 843-859.

[46] Strowbridge, N. R. (2020). Intraspecific variation and plasticity in rainbow trout responses to climate change stressors (Doctoral dissertation, University of British Columbia).

[47] USDA (United States Department of Agriculture). (2013). Climate Change and Agriculture in the United States: Effects and Adaptation. USDA technical bulletin, Washington, DC.

[48] Hoving, I. E., Hiemstra, S. J., and Dooren, H. J. Van. (2014). Adaptation of livestock systems to climate change; functions of grassland, breeding, health, and housing.

[49] Solomon, T., Ebrahim, H. (2018). Benefits of Farm Animals Genetic Adaptation: A Review. Dairy and Vet Sci J., 6(5): 555697. DOI: 10.19080/JDVS.2018.06.555697.

[50] Darcan, N. K. and Silanikove, N. (2018). The advantages of goats for future adaptation to Climate Change: A conceptual overview. Small Ruminant Research, 163, pp. 34-38.

[51] Sejian, V., Bhatta, R., Gaughan, J. B., Dunshea, F. R. and Lacetera, N. (2018). Adaptation of animals to heat stress. Animal, 12(s2), pp. s431-s444.

[52] Renaudeau, D., Collin, A., Yahav, S., De Basilio, V., Gourdine, J. L., and Collier, R. J. (2012). Adaptation to hot climate and strategies to alleviate heat stress in livestock production. Animal, 6, 707-728. 
[53] Zhang, Y. W., Hagerman, A. D., McCarl, B. (2013). Influence of climate factors on the spatial distribution of Texas cattle breeds. Clim. Chang., 118, 183-195.

[54] Zhang, Yuquan W. (2017). “An Overview of Mitigation and Adaptation Needs and Strategies for the Livestock Sector.” 1-15. DOI: 10.3390/cli5040095.

[55] Oliver, D. M., Fish, R. D., Winter, M., Hodgson, C. J., Heathwaite, A. L., and Chadwick, D. R. (2012). Valuing local knowledge as a source of expert data: farmer engagement and the design of decision support systems. Environ. Modell. Software, 36, 76-85.

[56] Jones, A. K., Jones, D. L., Edwards-Jones, G., Cross, P. (2013). Informing decision making in agricultural greenhouse gas mitigation policy: a best-worst scaling survey of expert and farmer opinion in the sheep industry. Environ. Sci. Policy, 29, 46-56.

[57] Barnes, A. P. (2013). Heterogeneity in climate change risk perception amongst dairy farmers: a latent class clustering analysis. Appl. Geogr., 41, 105-115.

[58] Chanza, N. and Gundu-Jakarasi, V. (2020). Deciphering the climate change conundrum in Zimbabwe: an exposition. Global Warming and Climate Change. 